\author{
Hee Jin Bae, \\ Tack Geun Cho, \\ Chang Hyun Kim, \\ Ho Kook Lee, \\ Jae Gon Moon, \\ Jong II Choi
}

\begin{abstract}
Department of Neurosurgery, Hallym University Kangnam Sacred Heart Hospital, Hallym University College of Medicine, Seoul, Korea
\end{abstract}

\section{Corresponding Author:}

\section{Tack Geun Cho}

Department of Neurosurgery,

Hallym University Kangnam

Sacred Heart Hospital, Hallym

University College of Medicine, 1

Singil-ro, Yeongdeungpo-gu, Seoul

07441, Korea

Tel: +82-2-829-5304

Fax: +82-2-833-0219

E-mail: jotak01@hallym.or.kr

Received: May 29, 2017

Revised: July 14, 2017

Accepted: August 21, 2017
Copyright (C) 2017 by The Korean Spinal Neurosurgery Society

This is an open access article distributed under the terms of the Creative Commons Attribution Non-Commercial License (http://creativecommons.org/licenses/by$\mathrm{nc} / 4.0 /$ ) which permits unrestricted noncommercial use, distribution, and reproduction in any medium, provided the original work is properly cited.

\title{
Aortic Injury during Transforaminal Lumbar Interbody Fusion
}

Aortic injury during transforaminal lumbar interbody fusion (TLIF) is a rare but severe complication. We experienced aortic injury during TLIF at L3-4 with a 59-year-old woman diagnosed with an adjacent segment disease at L3-4. Severe bleeding occurred during disc space expansion, and the blood pressure dropped to $60 / 40 \mathrm{mmHg}$. The patient's vital sign stabilized after compression with gauze and Gelfoam in addition to blood transfusion. The patient was treated with endovascular repair using a percutaneous technique after intertransverse fusion at L3-4 was completed. She recovered and is being followed-up in the outpatient department.

Key Words: Aortic rupture, False aneurysm, Intraoperative complications, Endovascular procedures, Intervertebral disc

\section{INTRODUCTION}

Transforaminal lumbar interbody fusion (TLIF) is one of the major surgical procedures for treating degenerative spinal diseases that result in instability ${ }^{12)}$, and is commonly performed due to its safety and positive prognosis. Some complications of TLIF are pseudoarthrosis with loosening of the implants, dural leakage, nerve root damage, and deep infection ${ }^{8)}$.

Aortic injury is another, more serious complication of TLIF. Surgeons should be cautious of aortic injury as, though infrequent, it is potentially fatal. Here, we present the case of a patient who experienced aortic injury during TLIF.

\section{CASE REPORT}

A 59-year-old woman visited the Emergency Department with a chief complaint of radiating pain from her back to her left thigh. The findings were positive in the straight leg raise test at $50^{\circ}$ on the left side and she had motor weakness on her left lower extremity classified as grade 3 in the manual muscle test.

She had been taking medications for hypertension, diabetes mellitus, and rheumatoid arthritis including steroids for 2 years. She had undergone 2 surgeries, specifically, aneurysm neck clipping of the right anterior communicating artery 10 years earlier, and TLIF at L4-5-S1 for spondylolisthesis at L4-5-S1.

T2-weighted magnetic resonance images showed high signal intensity at the $\mathrm{L}^{-}-4$ intervertebral disc, compression of the thecal sac by an L3-4 herniated nucleus pulposus, and unclear anterior longitudinal ligaments (ALLs) (Fig. 1). We diagnosed the patient with adjacent segment disease at $\mathrm{L}^{-4} 4$ and planned to perform TLIF at L3-4.

Within the operative field, the disc had been softened by necrosis. Severe bleeding occurred during disc space expansion with a reamer for interbody fusion. We tried to control the bleeding by immediate gauze-packing. The patient's blood pressure dropped to $60 / 40 \mathrm{mmHg}$ and norepinephrine was administered. Blood transfusion with 3 units of packed red blood cells was performed, followed by 2 units of fresh frozen plasma to maintain stable vital signs. After bleeding control succeeded following thirty minutes of compression and Cutanplast standard (Mascia Brunelli, Milano, Italy) packing, we confirmed that her vital sign was stable and there was no bleeding or oozing around posterior longitudinal ligament (PLL) within the operative field. Then, we continued with the spinal surgery by performing intertransverse fusion instead of interbody fusion, with close monitoring of her vital signs, which remained stable.

After the spinal surgery, we performed abdominal computed tomography angiography and found a pseudoaneurysm at the $\mathrm{L}^{-4}-4$ level, just $1 \mathrm{~cm}$ above the bifurcation of the abdominal aorta, with a size of approximately $2 \mathrm{~cm}$ on the right side (Figs. 2, 3).

On the day following the spinal surgery, through consultation with a cardiothoracic surgeon and an interventional radiologist, endovascular repair was performed using a percuta 

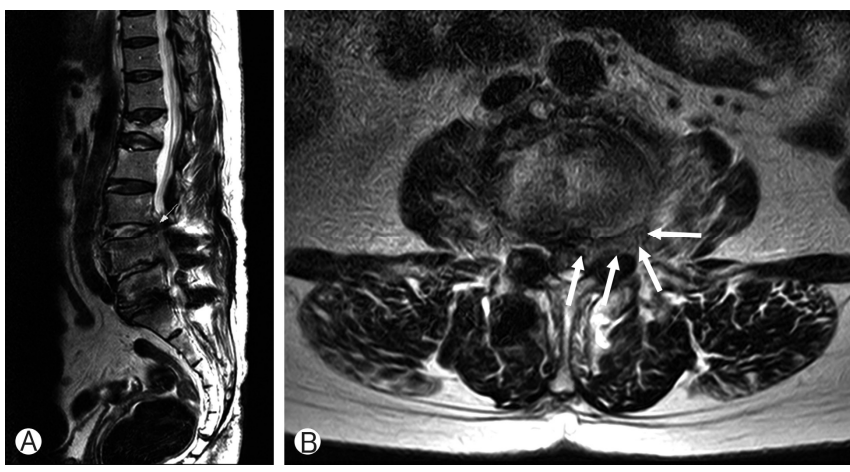

Fig. 1. Preoperative T2-weighted magnetic resonance image of the lumbar spine. (A) The L3-4 intervertebral disc has high signal intensity on the sagittal image. (B) L3-4 disc herniation (arrows) showing protrusion to the left $\mathrm{L} 3-4$ foramen is indicated on the axial image.

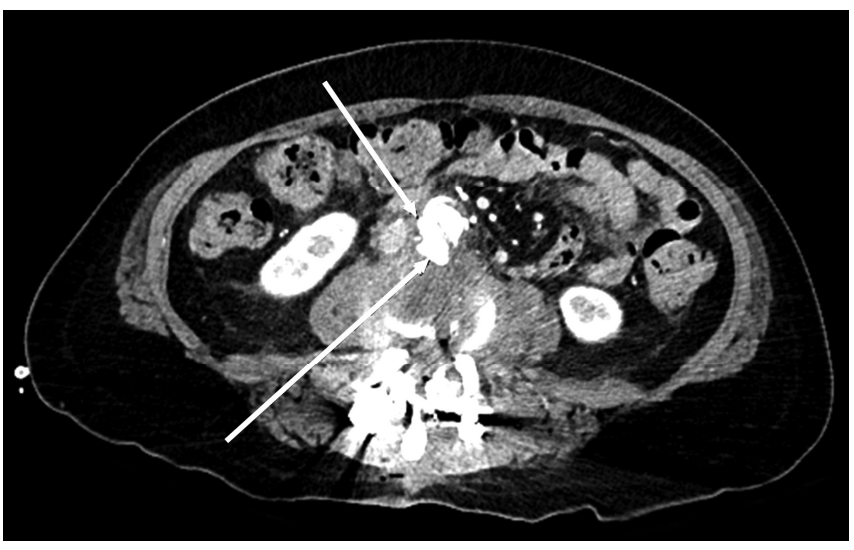

Fig. 2. Postoperative abdominal computed tomography angiography image shows irregular lobulated contrast media collection (arrows), $2.4 \mathrm{~cm} \times 1.4 \mathrm{~cm}$ at the right side of the abdominal aorta, indicating pseudoaneurysm at the L3-4 level.

neous technique, and a seal stent graft Limb-18-60 (S\&G Biotech Inc., Seoul, Korea) was inserted. After obtaining angiographic confirmation of the absence of endoleakage (Fig. 4), the patient recovered well and has been visiting the outpatient department for follow-up.

\section{DISCUSSION}

Aortic injury during TLIF is known to be a rare complication. The incidence is reported to range from $0.01 \%-0.06 \% \%^{5,10)}$. However, it is probably more frequent because there may be many misdiagnosed cases due to the variety of clinical symptoms, making diagnosis difficult ${ }^{2}$. The mortality rate for diagnosed cases is between $15 \%$ and $65 \% \%^{5-7}$. Mortality depends on the diameter of the injured vessel, size of the tear, rapidity of diagnosis, laparotomy, and amount of control over bleeding ${ }^{5,7,10)}$.

The complications of aortic injury during TLIF are divided
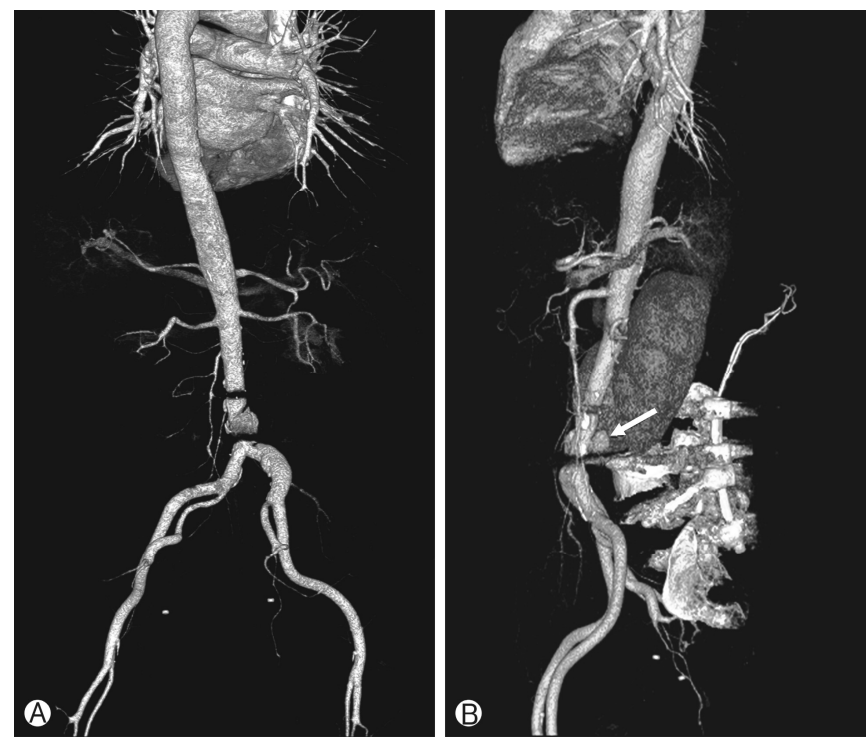

Fig. 3. Three-dimensional reconstruction image of postoperative abdominal computed tomography angiography. The posterior-anterior view (A) and the left lateral view (B) of the abdominal aorta show pseudoaneurysm (arrow).

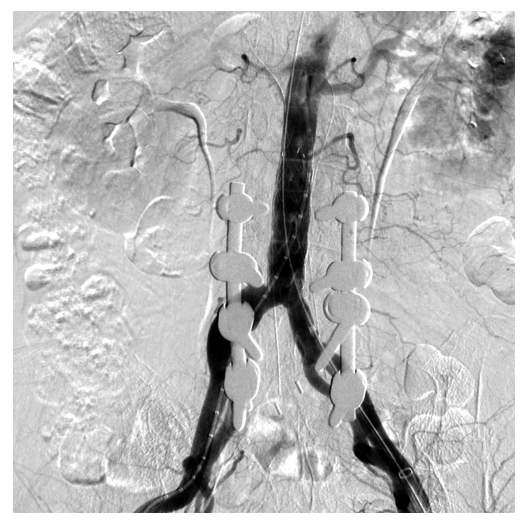

Fig. 4. Postendovascular repair angiography shows the absence of endoleakage.

into early and late complications. Early complications include shock due to a rupture of the major retroperitoneal vessel, while pseudoaneurysms and arteriovenous fistulas can occur years after the surgery ${ }^{4,9)}$. Since anterior annulus fibrosus and ALL are tough and elastic, they can cause bleeding into the retroperitoneal space, making the bleeding difficult to see ${ }^{13)}$.

Preoperative preparations - such as history taking and imaging study, including MRI - are important for prevention. Some findings should be confirmed with MRI if there is any defect on the anterior annulus fibrosus or ALL, peridiscal fibrosis with vessel adhesion and scarring following a previous abdominal surgery or radiotherapy, or pathological weakness of the vascular wall due to degeneration or erosion of the ventral disc herniation or osteophytic spurs. We suspect that there were adhesions and fibrosis within the aorta and disc caused by necrosis of the disc, and this was the reason for the aortic injury during disc expansion.

The aorta and the pelvic vessels may not have been in their 
normal anatomic locations or may have been tortuous due to anomalies within them. It is also recommended to check the depth and contour of the disc space, as well as any anatomic variants that could increase risk. Since the distance from the aorta to the vertebrae varies with abdominal pressure, which is affected by the position of a patient, the patient should be positioned carefully. Because the sagittal diameter of the three lowest lumbar disc ranges from 33 to $56 \mathrm{~mm}^{1)}$, advancing instruments less than $3 \mathrm{~cm}$ from the posterior disc border may be a good method to prevent aortic injury ${ }^{13)}$.

If complications occur despite efforts to prevent injury, the clinical manifestations would be abdominal pain, dyspnea, back pain, or shock ${ }^{3}$. However, it is difficult to detect these symptoms because the patient assumes a prone position under general anesthesia.

Angiography is more helpful than computed tomography scans for diagnosing aortic injury because it provides much more information about vascular anatomy and injury. Early diagnosis in addition to immediate surgical repair is necessary for this condition. While surgery has a higher mortality rate due to hemodynamic instability, endovascular surgery has better outcomes with regard to mortality and morbidity because of its minimal invasiveness ${ }^{3)}$.

When aortic injury occurs, the planned spinal surgery may be postponed until the injury is completely repaired. Aortic injury during TLIF should be treated promptly ${ }^{11)}$ because the injured vessel walls become weaker, making it difficult to suture the injured aorta. In addition, disseminated intravascular coagulation can occur over time.

In this case, we debated whether to complete the spinal surgery before aortic repair or to perform an aortic repair immediately. If we had stopped the spinal surgery and performed an aortic repair immediately, she would have had to undergo additional surgery for TLIF later. The patient had a sensitive and anxious personality. She was worried about having a reoperation at the adjacent segment that had previous undergone surgery on the lumbar lesion. At that moment, it was urgent to treat the aortic repair. However, considering the patient's sensitive condition, we considered that the spinal surgery could be completed if her vital sign was stable during the surgery. Fortunately, we could control bleeding over the operative field and her vital sign kept being stable. Also, there was no oozing over PLL part and the surgery was completed. It might not be a good decision to treat the aortic injury on the next day after the spinal surgery. Because it could be dangerous if the complications of aortic injury occurred, it should be treated on the day of spinal surgery.

\section{CONCLUSION}

We present the case of a patient who experienced aortic injury during TLIF and underwent the spinal surgery before the aortic injury repair. We discovered that it is possible to complete spinal surgery if the patient is in a hemodynamically stable condition even after aortic injury.

\section{CONFLICT OF INTEREST}

No potential conflict of interest relevant to this article was reported.

\section{REFERENCES}

1. Anda S, Aakhus S, Skaanes KO, Sande E, Schrader H: Anterior perforations in lumbar discectomies. A report of four cases of vascular complications and a CT study of the prevertebral lumbar anatomy. Spine (Phila Pa 1976) 16:54-60, 1991

2. Canaud L, Hireche K, Joyeux F, D'Annoville T, Berthet JP, MartyAné C, et al: Endovascular repair of aorto-iliac artery injuries after lumbar-spine surgery. Eur J Vasc Endovasc Surg 42:167-171, 2011

3. Chao CM, Wu CD, Sung KC, Lin WT, Lee KK, Lai CC: Right iliac aortic aneurysmal hemorrhage as a complication of lumbar discectomy. World Neurosurg 80:901.e7-8, 2013

4. Döşoğlu M, Iş M, Pehlivan M, Yildiz KH: Nightmare of lumbar disc surgery: iliac artery injury. Clin Neurol Neurosurg 108:174177, 2006

5. Ewah B, Calder I: Intraoperative death during lumbar discectomy. Br J Anaesth 66:721-723, 1991

6. Franzini M, Altana P, Annessi V, Lodini V: Iatrogenic vascular injuries following lumbar disc surgery. Case report and review of the literature. J Cardiovasc Surg (Torino) 28:727-730, 1987

7. Goodkin R, Laska LL: Vascular and visceral injuries associated with lumbar disc surgery: medicolegal implications. Surg Neurol 49: 358-370, 1998

8. Harms JG, Jeszenszky D: Die posteriore, lumbale, interkorporelle Fusion in unilateraler transforaminaler Technik. Oper Orthop Traumatol 10:90-102, 1998

9. Kwon TW, Sung KB, Cho YP, Kim DK, Ko GY, Yoon HK, et al: Large vessel injury following operation for a herniated lumbar disc. Ann Vasc Surg 17:438-444, 2003

10. Papadoulas S, Konstantinou D, Kourea HP, Kritikos N, Haftouras N, Tsolakis JA: Vascular injury complicating lumbar disc surgery. A systematic review. Eur J Vasc Endovasc Surg 24:189-195, 2002

11. Park HK, Choe WJ, Koh YC, Park SW: Endovascular management of great vessel injury following lumbar microdiscectomy. Korean J Spine 10:264-267, 2013

12. Resnick DK, Choudhri TF, Dailey AT, Groff MW, Khoo L, Matz PG, et al: Guidelines for the performance of fusion procedures for degenerative disease of the lumbar spine. Part 7: intractable low-back pain without stenosis or spondylolisthesis. J Neurosurg Spine 2:670-672, 2005

13. Yip SL, Woo SB, Kwok TK, Mak KH: Nightmare of lumbar diskectomy: aorta laceration. Spine (Phila Pa 1976) 36:E1758-1760, 2011 